\title{
Time History Analysis of a Steel Water Tank with Pinned and Fixed Foundations under Varying Ground Perturbations
}

\author{
S. O. Odeyemi ${ }^{1 *}$, M. A. Akinpelu ${ }^{1}$, O. D. Atoyebi ${ }^{2}$, A. A. Ismail ${ }^{1}$ \\ ${ }^{1}$ Department of Civil Engineering, Kwara State University, Malete, Nigeria. \\ ${ }^{2}$ Department of Civil Engineering, Landmark University, Omu-Aran, Kwara State, Nigeria.
}

\begin{abstract}
Earthquake is a natural phenomenon which is caused by sudden release of energy in the Earth's crust that creates seismic waves. Seismic response of an overhead water tank with varying foundation types subjected to five different earthquake accelerograms was simulated using Time History Analysis. Tank responses observed includes the base shear, base moment and displacement at some joints. The maximum base shear obtained was $9.521 \mathrm{E}+03 \mathrm{kN}$ and $1.093 \mathrm{E}+04 \mathrm{kN}$ for pinned and fixed foundations respectively. The maximum displacements at three selected joints labelled as joint 12, joint 22 and joint 32 were $3.67 \mathrm{E}-01 \mathrm{~m}, 4.349 \mathrm{E}-01 \mathrm{~m}$ and $3.67 \mathrm{E}-01 \mathrm{~m}$ for pinned foundation and $8.68 \mathrm{E}-02 \mathrm{~m}, 1.119 \mathrm{E}-01 \mathrm{~m}$ and $8.68 \mathrm{E}-01 \mathrm{~m}$ when the foundations were fixed. The results revealed that using a fixed foundation increased the base shear but reduced displacements at the selected joints when compared to when a pinned foundation was used.
\end{abstract}

KEYWORDS: accelerogram, base shear, displacement, time history analysis, water tank stand.

[Received October 26 2017; Revised December 26 2017; Accepted March 24 2018]

\section{INTRODUCTION}

An elevated water tank is a large water storage container constructed for the purpose of holding water at certain height to pressurize the water distribution system. Elevated water tanks are critical and strategic structures and damage of these structures during earthquakes may endanger drinking water supply, cause failure in preventing large fires and result in substantial economic loss (Khadiranaikar, 2014). Water tanks play an important role in municipal water supply, firefighting systems and in many industrial facilities for storage of water. They are usually installed on a supporting tower, thereby instead of requiring heavy pumping facilities; the required pressure can be obtained by gravity (Raghavendra, 2014). Structures located in seismically active areas have to withstand lateral forces generated by earthquakes in addition to their primary purpose of carrying gravity loads.

An earthquake occurs as a result of sudden discharge of energy in the Earth's crust that generates seismic waves. Earthquakes are mostly caused by rupture of geological faults, but can also be as a result of volcanic activities, landslides, mine blasts, and nuclear experiments. Human activities such as construction of large dams and buildings, drilling and injecting liquid into wells, oil drilling and coal mining also causes earthquakes (Odeyemi, 2014). Of all the causes of earthquakes, naturally occurring tectonic-related earthquakes are the most significant (Chen and Liu, 2006). They are caused by the breakage and sliding of rock along faults (a zone of the earth's crust in which there is a movement of two sides) within the Earth's crust. Earthquakes cause a number of seismic hazards, which can cause significant damage to the built environment such as fault

*Corresponding author’s e-mail address: samson.odeyemi@kwasu.edu.ng rupture, vibratory ground motion or shaking, inundation like tsunami and dam failures, permanent ground failures, fire, or release of hazardous materials.

The initial point of rupture of an earthquake where the fault movement begins is called its hypocentre. The ground level directly above the hypocentre is called the epicentre (Chen and Liu, 2006). The analysis of earthquakes requires measurement. Before the inventions of seismometers (an instrument for measuring earthquakes), earthquakes were measured by their intensity which differed from point to point. With the deployment of seismometers, the unique magnitude of an earthquake became possible. Time History method of analysis is an Engineering approach of measuring earthquake phenomena for analysis (Chen and Liu, 2006).

This research aims to carry out a seismic analysis on a steel water tank stand subjected to varying magnitude of earthquake using the Time History method of seismic analysis.

\section{A. Earthquakes in Nigeria}

Nigeria has at various times experienced magnitudes of earthquakes ranging from 4.3 to 4.5 resulting in loss of properties (Odeyemi and Adedeji, 2013). In 2016, Shaki, a town in Oyo State experienced some tremors which ranged from III to IV on the Modified Mercalli Intensity Scale (Orakpo, 2017). On July 10, 2016, border towns of Bayelsa and Rivers were hit with tremors which seriously damaged some structures. On 11th and 12th September, 2016, earthquakes of magnitude 2.6 to 3.0 affected Kwoi and surrounding villages of Nok, Sanbang Daji and Chori in 
Kaduna State. These were recorded by the seismic station at Kujama in Kaduna State (Orakpo, 2017). Thus, Nigeria cannot be classified as an earthquake-free zone. This development requires that measures be put in place to mitigate earthquake occurrence in the country.

\section{B. Time History Analysis}

Time history analysis is the study of the dynamic response of a structure at every addition of time, when its base is exposed to a particular ground motion. Seismometers are used to record actual ground motions specific to a location. Typically, the ground motion records known as Time histories have recorded accelerograms for many years in analog form on photographic film or digitally. Time histories contain comprehensive information about the motion at the instrumental location, recording three traces or orthogonal records (two horizontal and one vertical). The maximum amplitude of recorded accelerogram is termed the peak ground acceleration (PGA). The peak ground velocity (PGV) and peak ground displacement (PGD) are the maximum respective amplitudes of velocity and displacement (Odeyemi, 2014).

The Time History method is extremely efficient and is designed to be used for structural systems which are linearly elastic, but which have a limited number of pre-defined nonlinear elements. It is assumed that all nonlinearity is restricted to the Link/Support elements. The dynamic equilibrium equations of a linearly elastic structure with predefined nonlinear Link/Support elements subjected to an arbitrary load can be written as (Computers and Structures Inc., 2010):

$$
K_{L} U(t)+C \dot{u}(t)+M \ddot{u}(t)+r_{N}(t)=r(t)
$$

where;

$\mathrm{K}_{\mathrm{L}}$ is the stiffness matrix for the linear elastic elements;

$\mathrm{C}$ is the proportional damping matrix;

$\mathrm{M}$ is the diagonal mass matrix;

$r_{\mathrm{N}}$ is the vector of forces from the nonlinear degrees of freedom in the Link/Support elements;

$U, \dot{u}$ and $\ddot{u}$ are the relative displacements, velocities, and accelerations with respect to the ground; and $r$ is the vector of applied load.

Most structures are multi-degree of freedom systems with multiple modes of vibration. Each mode has an associated period. The longest period is called the fundamental or natural period (Martini, 2012). The modal frequency of a structure is the number of cycles of vibration of a mode shape carried out in the unit of time. This is dependent only on the stiffness and the mass which participates with the structure (including self-weight) but not dependent on the load function. The knowledge of the modal frequencies of a structure helps to ensure that the frequency of any applied periodic loading will not coincide with its modal frequency thus preventing resonance, which leads to large oscillations.

\section{Time Support Connection and Base Shear}

Structural members are connected in several ways depending on the intent of the designer. Three types of joint restraints often specified are the roller support, pin connection and the fixed joint. A roller support and a pin-connected joint allow some freedom for slight rotation, whereas a fixed joint allows no relative rotation between the connected members (Hibbeler, 2012).

Base shear is an estimate of the maximum expected lateral force that will occur due to seismic ground motion at the base of a structure. Base shear $(\mathrm{V})$ depends on:

1. Soil conditions at the site;

2. Proximity to potential sources of seismic activity (such as geological faults);

3. Probability of significant seismic ground motion;

4. The level of ductility and over strength associated with various structural configurations and the total weight of the structure;

5. The fundamental (natural) period of vibration of the structure when subjected to dynamic loading.

\section{Analysis Simulation using SAP2000}

Adedeji and Ige (2010) recommended SAP2000 as a worthy software for dynamic and static analysis of structures based on the following points:

i. It has in-built ground motion records which other do not possess;

ii. It is versatile in handling various types of analysis either linear or non-linear;

iii. It has a user friendly graphical interface;

iv. It possesses numerous code of practice; and

v. It has been certified by several professionals through-out the world to be one of the best dynamic analysis packages.

\section{METHODOLOGY}

A $5 \mathrm{~m}$ high steel water tank stand was modelled and analysed in this study. The stand has six (6) columns, three (3) and six (6) secondary beams made of $127 \times 76 \times 13$ Universal Beams (UB). There are 18 diagonal bracings and 15 horizontal bracings made from 40 X 40 X 3 Equal Angles (EA). The steel stand is located in Kwara State University, Malete, Kwara State. An extruded 3D SAP2000 model of the stand is shown in Figure 1. 


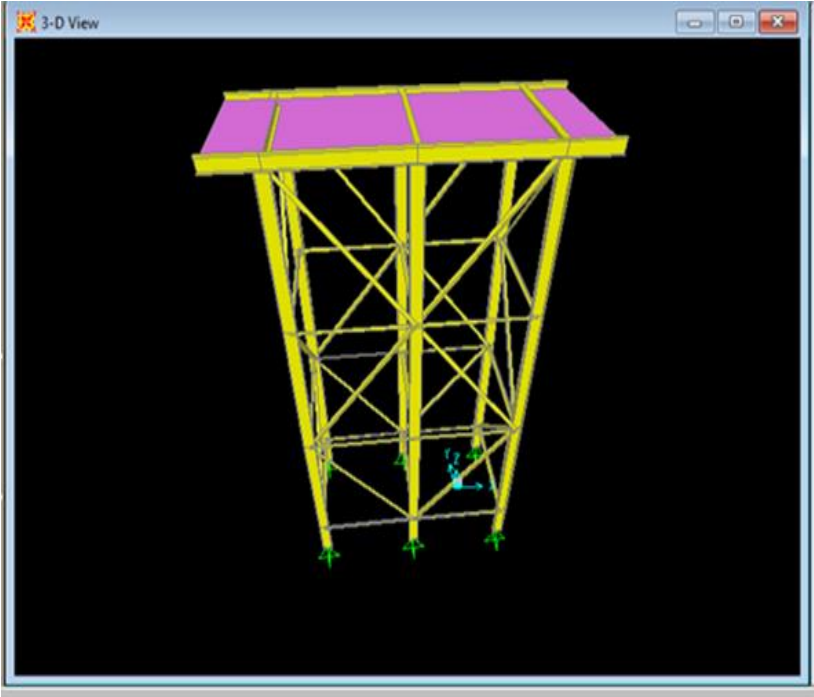

Figure 1: A 3D model of a Steel Water Tank Stand.

The model was subjected in addition to its self-weight and the imposed load to five different recorded accelerograms namely Elcentro Earthquake, Newhall Earthquake, Pomona Earthquake, Santa-Monica Earthquake and Petrolia Earthquake. The magnitudes of these earthquakes are 6.9, 6.7, 6.7, 6.7 and 7.2 respectively. Kamara and Katale (2013) recommended that series of earthquake records should be used instead of jusapet one when carrying out Time History analysis because exact response of a structure to seismic loads or actions cannot be predicted with only one earthquake record since the occurrence of earthquakes is based on probabilities. The foundations of the water tank stand were varied between fixed and pinned supports under the different cases.

\section{RESULTS AND DISCUSSION}

\section{A. Modal Shape}

Table 1 shows the Natural periods (T) and modal frequencies (F) of the first five deformed (Modal) shape of the Stand when subjected to the earthquake accelerograms under pin and fixed foundations.
The results revealed that the frequency of the earthquake when the foundation was fixed was higher when compared to when the structure was pinned. Thus, there will be more vibrations in a given time when the foundation is fixed than when it is pinned. The modal shapes of the structure when the foundations were pinned are shown in Figure 2 to Figure 6 and in Figure 7 to Figure 11 when the foundations were fixed.

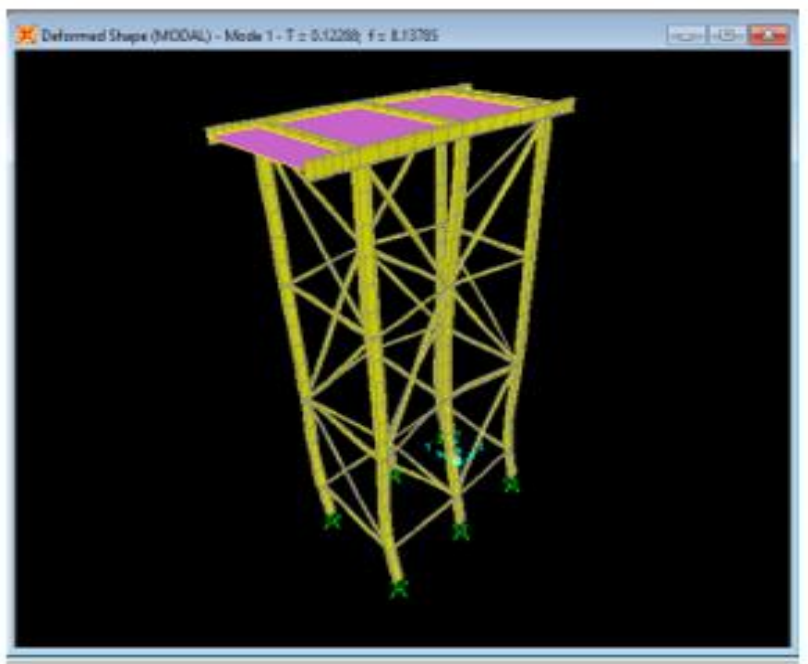

Figure 2: Modal Shape 1 under Pinned Support.

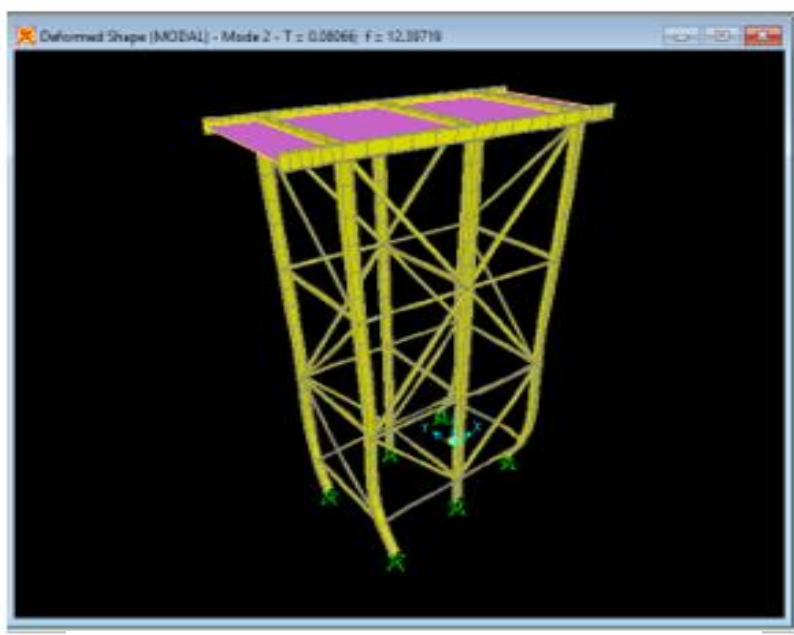

Figure 3: Modal Shape 2 under Pinned Support.

Table 1: Natural Period and Frequency of the First Five Deformed (Modal) Shape of the Stand when subjected to Earthquake and under Pin Foundation and Fixed Foundation.

\begin{tabular}{|c|c|c|c|c|c|c|c|c|c|c|}
\hline \multirow[t]{2}{*}{ Foundation Type } & \multicolumn{2}{|c|}{ Mode 1} & \multicolumn{2}{|c|}{ Mode 2} & \multicolumn{2}{|c|}{ Mode 3} & \multicolumn{2}{|c|}{ Mode 4} & \multicolumn{2}{|c|}{ Mode 5} \\
\hline & T (sec) & $F\left(\sec ^{-1}\right)$ & $\mathbf{T}(\mathrm{sec})$ & $F\left(\sec ^{-1}\right)$ & $\mathbf{T}(\mathrm{sec})$ & $F\left(\sec ^{-1}\right)$ & $\mathbf{T}(\mathrm{sec})$ & $F\left(\sec ^{-1}\right)$ & $\mathbf{T}$ (sec) & $F\left(\sec ^{-1}\right)$ \\
\hline $\begin{array}{l}\text { Pinned (to be } \\
\text { consistent with } 2-5 \text { ) }\end{array}$ & 0.12288 & 8.13785 & 0.08066 & 12.39719 & 0.07744 & 12.91327 & 0.05678 & 17.61238 & 0.04748 & 21.06083 \\
\hline $\begin{array}{l}\text { Fixed (to be } \\
\text { consistent with } \\
\text { Tables } 2-5 \text { ) }\end{array}$ & 0.08860 & 11.28683 & 0.06188 & 16.16026 & 0.05156 & 19.39512 & 0.04462 & 22.40968 & 0.04114 & 24.30638 \\
\hline
\end{tabular}




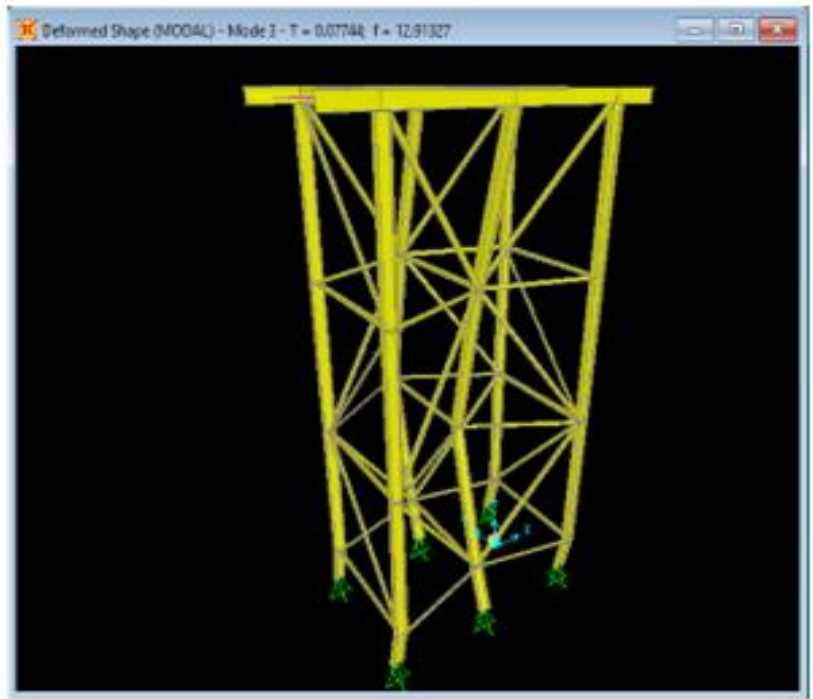

Figure 4: Modal Shape 3 under Pinned Support.

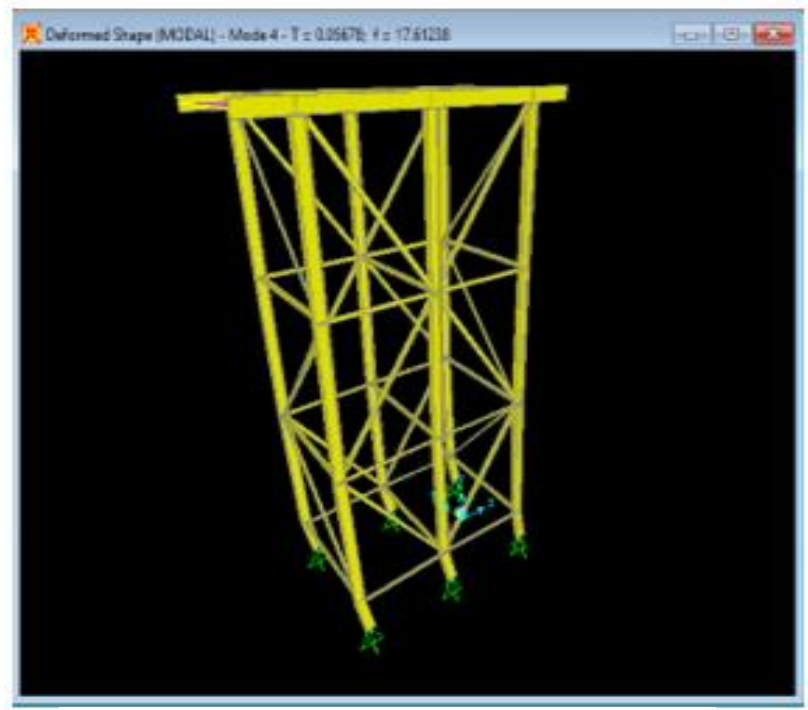

Figure 5: Modal Shape 4 under Pinned Support.

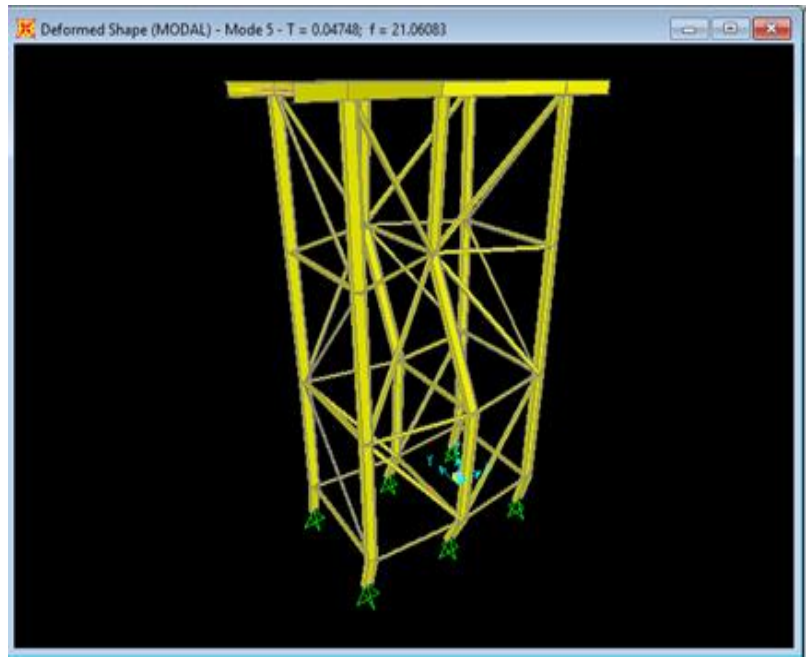

Figure 6: Modal Shape 5 under Pinned Support.

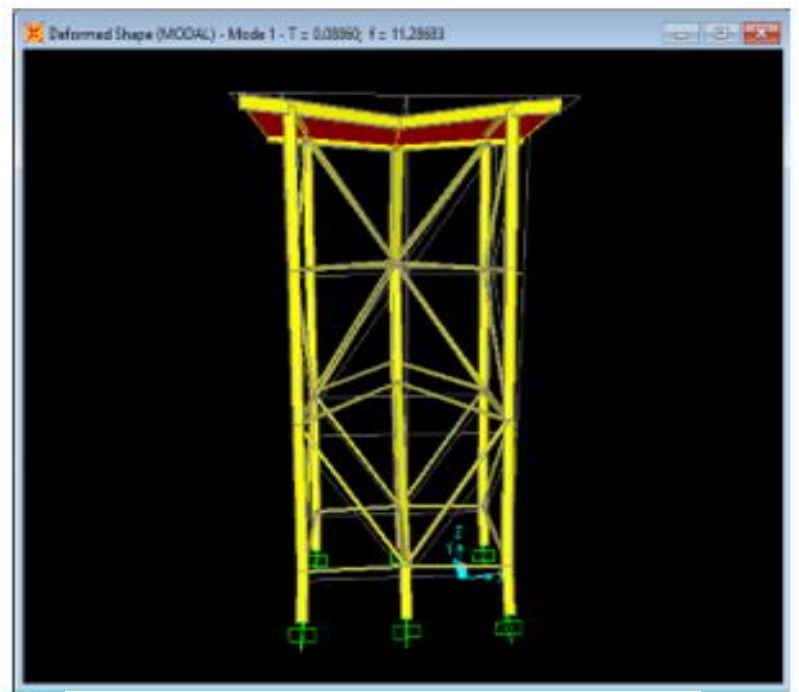

Figure 7: Modal Shape 1 under Fixed Support.

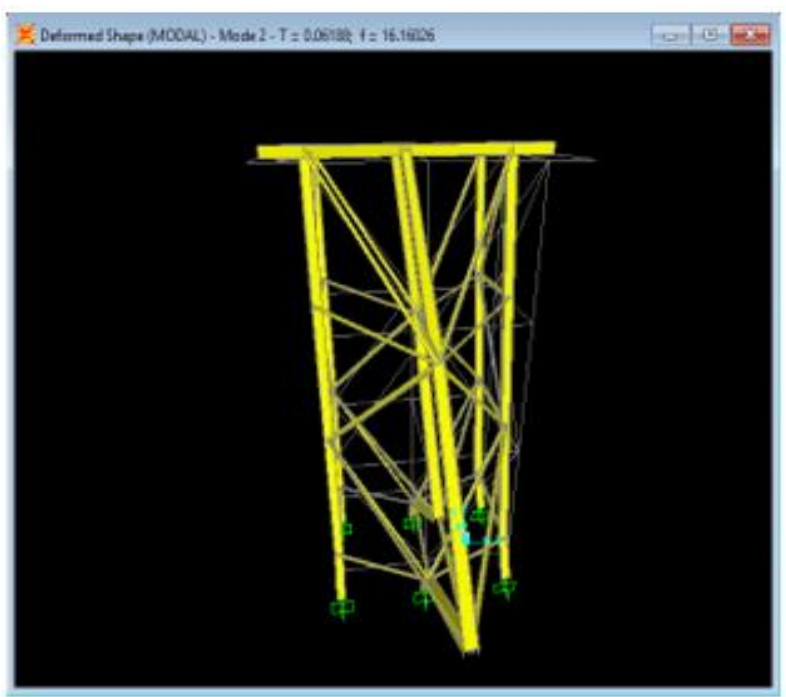

Figure 8: Modal Shape 2 under Fixed Support.

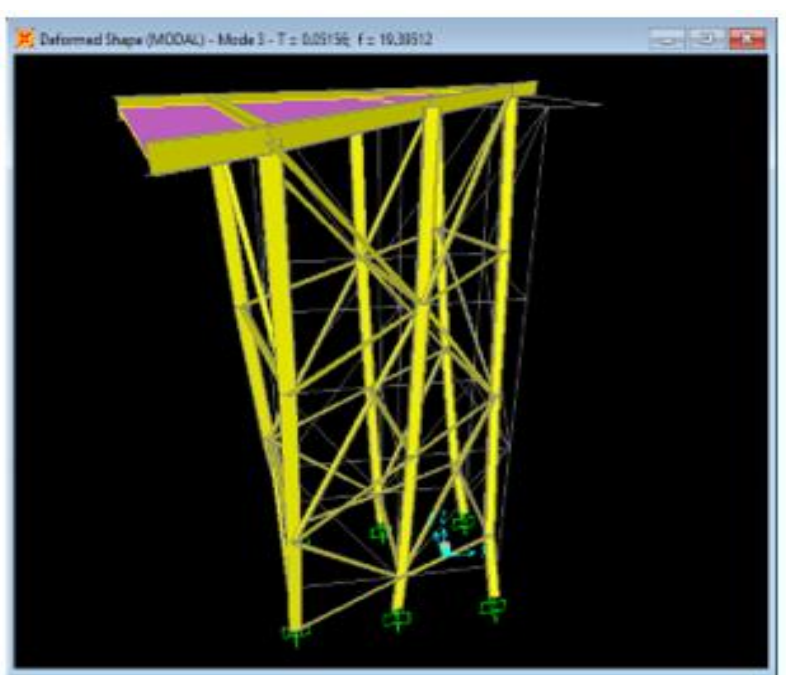

Figure 9: Modal Shape 3 under Fixed Support. 


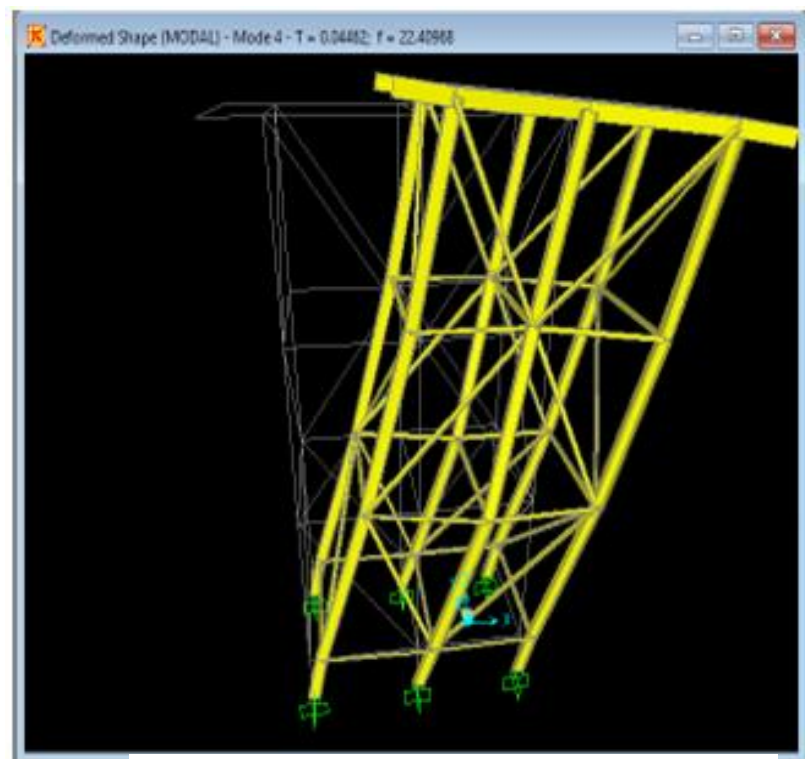

Figure 10: Modal Shape 4 under Fixed Support

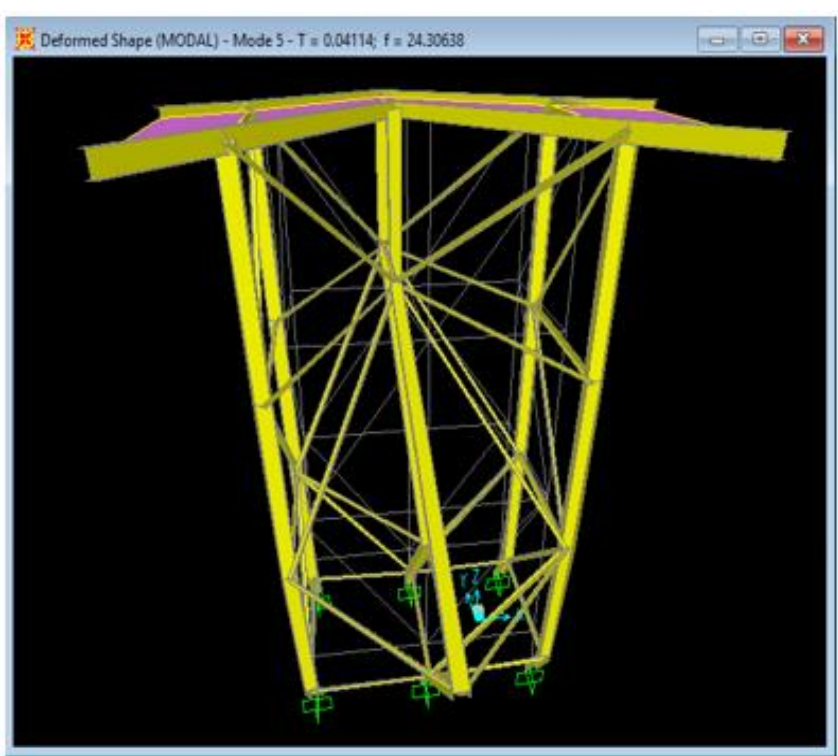

Figure 11: Modal Shape 5 under Fixed Support.

Table 2: Minimum and Maximum Base Shears for the Tank Stand

\begin{tabular}{|c|c|c|c|c|c|c|c|c|c|c|}
\hline $\begin{array}{l}\text { Foundation } \\
\text { Type }\end{array}$ & \multicolumn{2}{|c|}{ Elcentro } & \multicolumn{2}{|c|}{ Newhall } & \multicolumn{2}{|c|}{ Pomona } & \multicolumn{2}{|c|}{ Santa monica } & \multicolumn{2}{|c|}{ Petrolia } \\
\hline Pinned & $-2.576 \mathrm{E}+00$ & $2.339 \mathrm{E}+00$ & $-7.560 \mathrm{E}+03$ & $8.614 \mathrm{E}+03$ & $-3.088 \mathrm{E}+03$ & $3.262 \mathrm{E}+03$ & $-8.956 \mathrm{E}+03$ & $9.521 \mathrm{E}+03$ & $-9.049 \mathrm{E}+03$ & $9.505 \mathrm{E}+03$ \\
\hline Fixed & $-2.333 E+00$ & $2.168 \mathrm{E}+00$ & $-9.153 E+03$ & $8.942 \mathrm{E}+03$ & $-2.049 \mathrm{E}+03$ & $2.230 \mathrm{E}+03$ & $-1.032 \mathrm{E}+04$ & $1.093 \mathrm{E}+04$ & $-1.043 \mathrm{E}+04$ & $1.091 \mathrm{E}+04$ \\
\hline
\end{tabular}

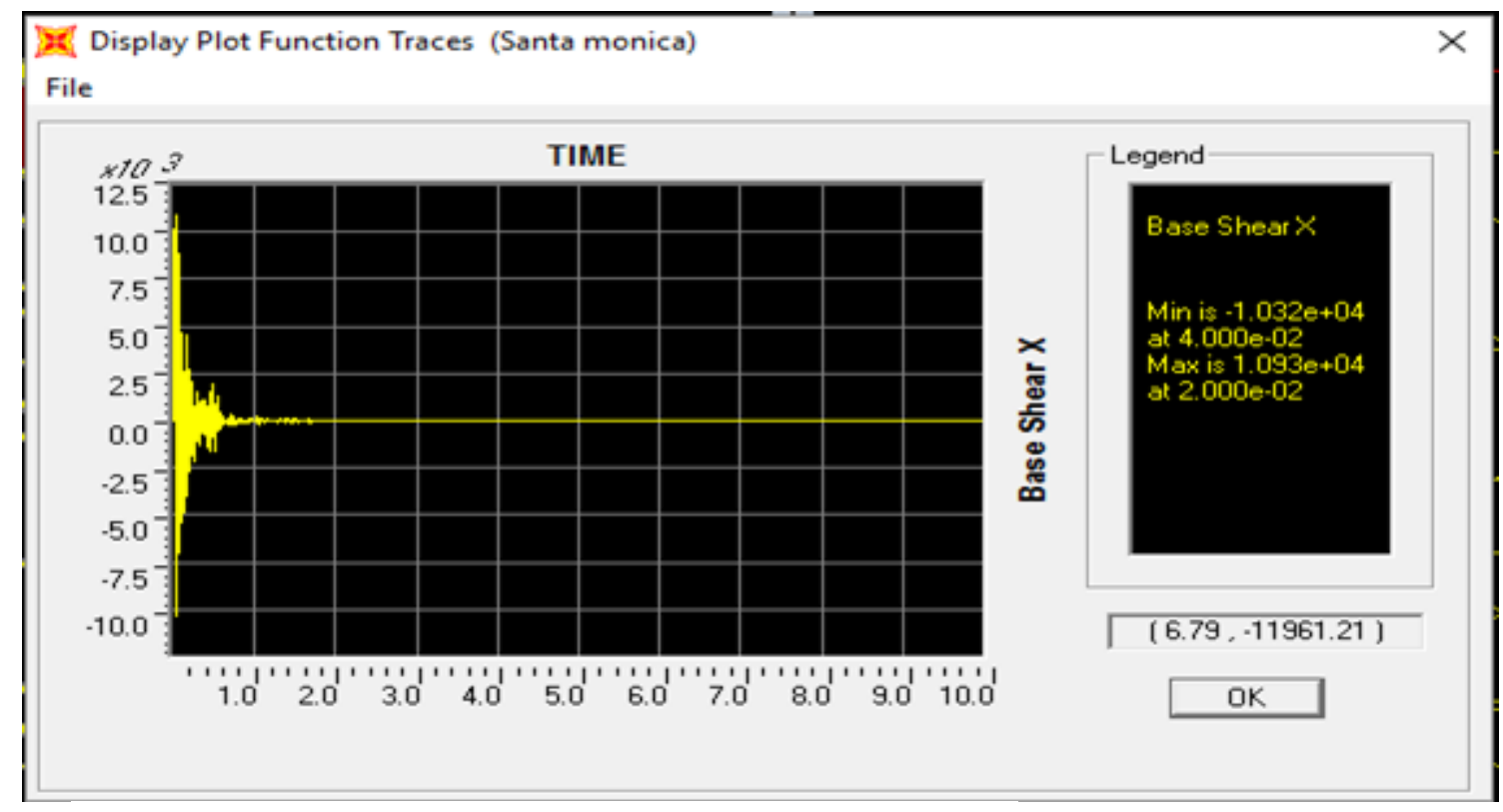

Figure 12: Base Shear for Fixed Support for Santa Monica Earthquake. 


\section{B. Base Shear}

The minimum and maximum values for the base shears for the simulated earthquake scenarios are shown in Table 2. The maximum base shear of $1.093 * 104 \mathrm{kN}$ was recorded when the foundation was fixed under the Santa Monica Earthquake. The time history plot of the maximum base shear is shown in Figure 12.

\section{Joints Displacements}

The displacements at joints 12, 22 and 32 which are close to the foundations were investigated for both foundation types. The joint designations are shown in Figure 13. The results obtained are shown in Table 3, Table 4 and Table 5 for Joint 12, 22, and 32 respectively. The maximum displacement was noted at Joint 22 under the Petrolia earthquake with a value of $4.35 * 10-1 \mathrm{~m}$ when the stand was pinned. It was observed that fixing the foundation brought about a reduction in the displacements at the joints. The Time History curve for Joint 22 under Petrolia earthquake is shown in Figure 14.

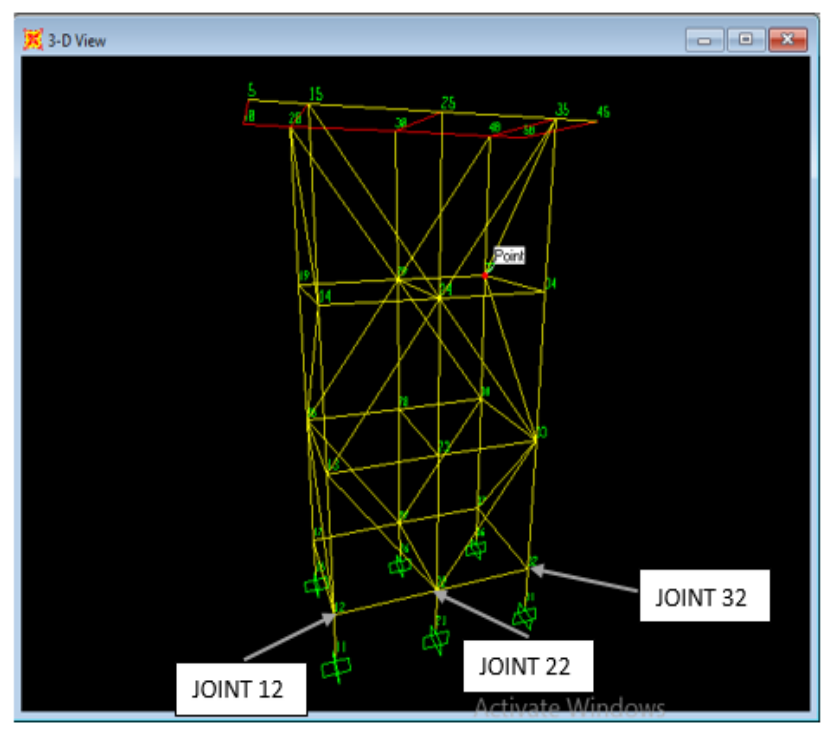

Figure 13: Framed Model of the Steel Stand showing Joints 12, 22 and 32.

Table 3: Minimum and Maximum Displacements for Joint 12.

\begin{tabular}{cccccccccccc}
\hline & \multicolumn{2}{c}{ Elcentro } & \multicolumn{2}{c}{ Newhall } & \multicolumn{2}{c}{ Pomona } & \multicolumn{3}{c}{ Santa monica } \\
\cline { 2 - 10 } Foundation Type & Min (m) & Max $(\mathbf{m})$ & Min $(\mathbf{m})$ & Max $(\mathbf{m})$ & Min (m) & Max $(\mathbf{m})$ & Min $(\mathbf{m})$ & Max (m) & Min (m) & Max (m) \\
\hline Pinned & $-3.74 \mathrm{E}-03$ & $0.00 \mathrm{E}+00$ & $--4.15 \mathrm{E}-01$ & $3.64 \mathrm{E}-01$ & $--2.76 \mathrm{E}-01$ & $2.43 \mathrm{E}-01$ & $--2.76 \mathrm{E}-01$ & $2.43 \mathrm{E}-01$ & $--4.14 \mathrm{E}-01$ & $3.67 \mathrm{E}-01$ \\
\multirow{2}{*}{ Fixed } & $-1.76 \mathrm{E}-05$ & $1.90 \mathrm{E}-05$ & $-7.40 \mathrm{E}-02$ & $7.58 \mathrm{E}-02$ & $-1.85 \mathrm{E}-02$ & $1.68 \mathrm{E}-02$ & $-9.08 \mathrm{E}-02$ & $8.59 \mathrm{E}-02$ & $-9.06 \mathrm{E}-02$ & $8.68 \mathrm{E}-02$ \\
\hline
\end{tabular}

Table 4: Minimum and Maximum Displacements for Joint 22.

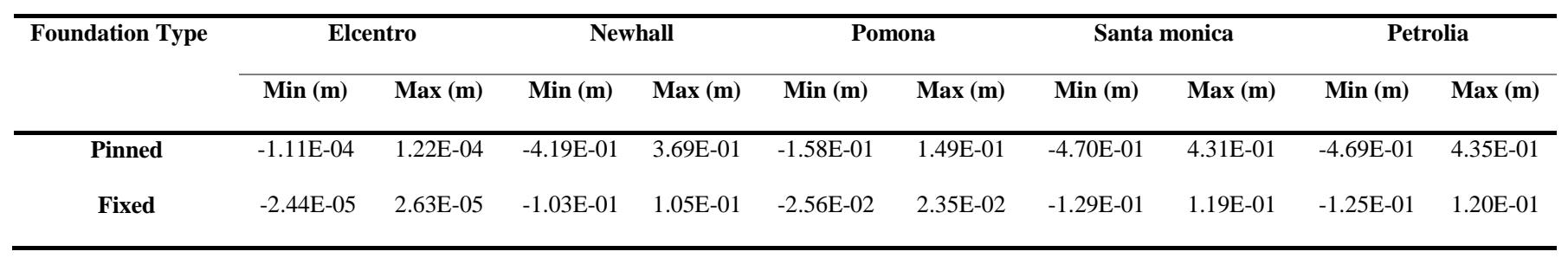

Table 5: Minimum and Maximum Displacements for Joint 32.

\begin{tabular}{|c|c|c|c|c|c|c|c|c|c|c|}
\hline \multirow[t]{2}{*}{ Foundation Type } & \multicolumn{2}{|c|}{ Elcentro } & \multicolumn{2}{|c|}{ Newhall } & \multicolumn{2}{|c|}{ Pomona } & \multicolumn{2}{|c|}{ Santa monica } & \multicolumn{2}{|c|}{ Petrolia } \\
\hline & $\operatorname{Min}(\mathbf{m})$ & Max (m) & $\operatorname{Min}(\mathbf{m})$ & $\operatorname{Max}(\mathbf{m})$ & $\operatorname{Min}(\mathbf{m})$ & $\operatorname{Max}(\mathbf{m})$ & $\operatorname{Min}(\mathbf{m})$ & Max (m) & $\operatorname{Min}(\mathbf{m})$ & $\operatorname{Max}(\mathbf{m})$ \\
\hline Pinned & $-3.74 \mathrm{E}-03$ & $0.00 \mathrm{E}+00$ & $-4.15 \mathrm{E}-01$ & $3.64 \mathrm{E}-01$ & $-2.76 \mathrm{E}-01$ & $2.43 \mathrm{E}-01$ & $-2.76 \mathrm{E}-01$ & $2.43 \mathrm{E}-01$ & $-4.14 \mathrm{E}-01$ & $3.67 \mathrm{E}-01$ \\
\hline Fixed & $-1.76 \mathrm{E}-05$ & $1.90 \mathrm{E}-05$ & $-7.40 \mathrm{E}-02$ & $7.58 \mathrm{E}-02$ & $-1.85 \mathrm{E}-02$ & $1.68 \mathrm{E}-02$ & $-9.08 \mathrm{E}-02$ & 8.59E-02 & $-9.06 \mathrm{E}-02$ & $8.68 \mathrm{E}-02$ \\
\hline
\end{tabular}




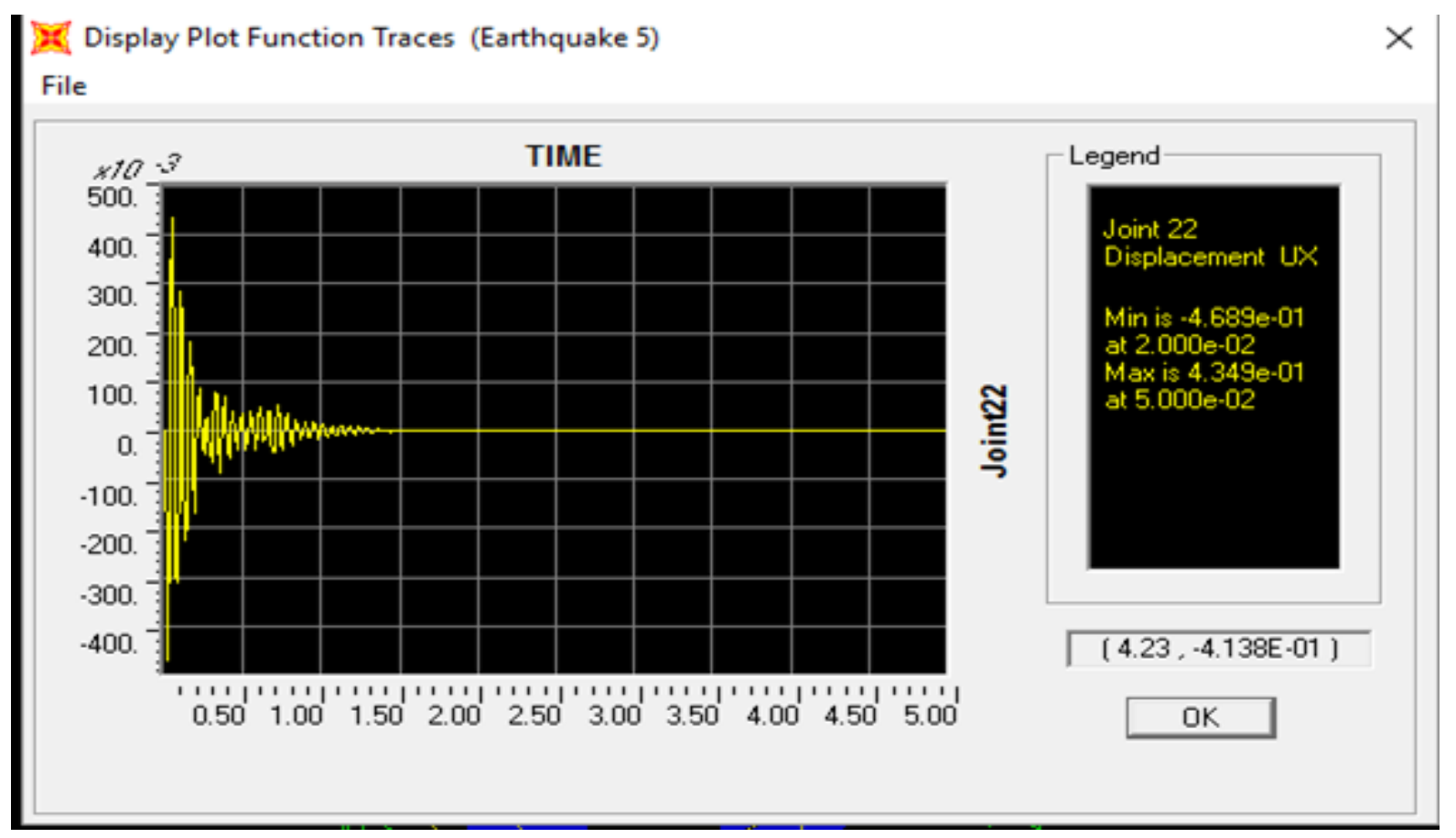

Figure 14: Time History curve for Joint 22 under Petrolia earthquake.

\section{CONCLUSION}

A water tank stand was analysed using the Time History method of seismic analysis when subjected to Elcentro, Newhall, Pomona, Santa-Monica and Petrolia Earthquakes each with magnitude of $6.9,6.7,6.7,6.7$ and 7.2 respectively. The analysis revealed that using a fixed foundation reduces the joint displacements of the tank in spite of increasing its base shear when compared to using a pinned foundation. Thus, fixed foundations will be more appropriate in mitigating earthquake occurrence in such structures.

\section{REFERENCES}

Adedeji, A. A. and Ige, S. P. (2011). Comparative Study of Seismic Analysis for Reinforced Concrete Frame Infilled with Masonry and Shape Memory Alloy Wire. Trends in Applied Science Research, 6 (5): 426-437.

Chen, W. F. and Lui, E. M. (2006). Earthquake Engineering for Structural Design. CRC Press; Taylor \& Francis Group, Boca Raton, U.S.A.

Computers and Structures Inc. (2010). CSI Analysis Reference Manual for SAP2000, ETABS, and SAFE. Computers and Structures Inc., Berkeley, California, U.S.A.

Hibbeler, R. C. (2012). Structural Analysis. Pearson Prentice Hall, Pearson Education Inc, Upper Saddle River, New Jersey, U.S.A

Kamara, V. S. and Katale, D. (2013). Dynamic Analysis of a Multistory 2D Truss Structure Subjected to
Seismic Loadings. Epistemics in Science, Engineering and Technology, 3 (2): 289-305.

Khadiranaikar, R. B. (2014). Equation for Estimation of Fundamental Time Period for Elevated Water Tank. International Journal of Civil Engineering and Technology, 5 (9): 266-275.

Martini, K. (2012). Dynamics in Building Design. Available online

at: http://www.arch.virginia.edu/ km6e/arch721/content/lectures /lec-05/. Accessed on December 22, 2017.

Odeyemi, S. O. (2014). Validation Analysis to Simulate Iyemoji Bridge Using Different Recorded Ground Motion Accelerograms. Websjournal of Science and Engineering Application, 3 (1): 164-178.

Odeyemi, S. O. and Adedeji, A. A. (2012). Comparative Study of Seismic Analysis for a Reinforced Concrete Bridge Column Reinforced with Steel and Shape Memory Alloy Wire. Epistemics in Science, Engineering and Technology, 2 (4): 224-232.

Orakpo, E. (2017). Earthquake in Nigeria: Measures to avert devastating impacts - Experts. Available online at: https://www.vanguardngr.com/2017/01/earthquake-nigeriameasures-avert-devastating-impacts-experts/. Accessed on January 4, 2017.

Raghavendra, G.; B. S. KeerthiGowda and M. H. Gururaj. (2014). Dynamic Analysis of Overhead Water Tank under Shaft Staging. International Journal of Advanced Scientific and Technical Research, 4 (3): 505-511. 